\title{
Ley del Botellón versus Ley de la Bota de Vino
}

\author{
Rodríguez-MARTos, A.
}

Secretaria de Socidrogalcoho

Enviar correspondencia a:

amartos@imsb.bcn.es

\section{RESUMEN}

Este editorial señala los problemas que han salido al paso del Anteproyecto de Ley de Prevención sobre el Consumo Indebido de Bebidas Alcohólicas, aprobado por el Consejo de Ministros en Mayo de 2002. El anuncio de este anteproyecto no satisfizo a las organizaciones agrícolas ni a la industria. Los productores de vino han reclamado y logrado que éste sea considerado como alimento en el Anteproyecto de la Ley de la Viña y el Vino. En consecuencia, también piden que el vino sea eliminado de la futura ley de prevención. Cabe preguntarse en qué quedará ésta.

Palabras clave: prevención, ley, alcohol, vino.

\section{SUMMARY}

This editorial points out the problems encountered by the Draft Law on alcohol abuse approved by the Council of Ministers in May 2002 and which is still on the way. The announcement of the draft law wasn't welcomed by the agricultural organisations and the alcohol industry. The wine producers have been claiming for wine to be considered as food, and have succeeded in having this declared within the new Draft Law on the Vineyard and the Wine. Accordingly, they've also asked to have the wine removed from the law on prevention. We wonder about its final version.

Key words: prevention, law, alcohol, wine
Anteproyecto de Ley de Prevención del Consumo Indebido de Bebidas Alcohólicas, anunciado por el ministro del Interior en Febrero de 2002 a los medios de comunicación con motivo del Congreso "Jóvenes, noche y alcohol" y aprobado en el Consejo de Ministros del 23 de mayo de 2002, ha ido suavizando su redactado atendiendo a diversas presiones y propuestas de enmiendas.

La Ley de Prevención del Consumo Indebido de Bebidas Alcohólicas se encuentra aún pendiente de aprobación por parte del congreso.

Según el último anteproyecto, la ley prohibirá el acceso al alcohol a los menores de 18 años, prohibirá el consumo en la vía pública de alcohol (siempre que se altere la tranquilidad ciudadana o el derecho a la libre circulación de las personas), contempla la restricción de horarios (prohibida la venta en horario nocturno en establecimientos donde no esté autorizado el consumo) y formas de venta (prohibición de la venta a domicilio, en áreas de servicio y gasolineras, exposición agrupada de las bebidas alcohólicas en los autoservicios...), así como nuevas restricciones a la publicidad (contenido, destinatarios y limitaciones horarias en televisión y radio, que no podrán emitir propaganda de bebidas de más de 20 grados de alcohol) y promoción de las bebidas alcohólicas. Las infracciones se sancionarán con multas de diversa cuantía y con la prestación de servicios a la comunidad, en el caso de menores. Se introducen medidas informativas sobre los efectos nocivos del alcohol mediante rótulos en los establecimientos de venta, dispensación o consumo. Se apuntan asimismo medidas educativas desde los ámbitos escolar (posibilidad de incluir educación preventiva del consumo abusivo de alcohol en los currículos), familiar y comunitario.

La Ley de Prevención no le gusta nada al sector productor. En efecto, en cuanto se tuvo conocimiento del primer anteproyecto, toda la industria puso el grito en el cielo, volviendo a la carga con ocasión de la Reunión de Expertos sobre marketing de bebidas alcohólicas organizada por la Organización Mundial de la Salud en mayo de 2002, en Valencia.

Las diversas organizaciones y comunidades agrarias como la Asociación de Jóvenes Agricultores (ASAJ), la Asociación Valenciana de Agricultores (AVA), la (UCAMAN) y la Confederación de Cooperativas Agrarias de España (CCAE), entre otras, canalizaron sus protestas a través del Consejo Económico y 
Social (CES), el Consejo de Consumidores y Usuarios (CCU) y la Federación Española de Municipios y Provincias (FEMP).

Los productores de vino reclaman la consideración del vino como alimento y, por consiguiente, su eliminación de la Ley de Prevención del Consumo Indebido de Bebidas Alcohólicas. Más aún, ASAJA considera que deberían hacerse apuestas más valientes de promoción del vino.

Basan sus reclamaciones no sólo en los perjuicios económicos que pudieran derivarse para el sector, sino también en las supuestas bondades del consumo moderado de vino, avaladas por estudios científicos. Aunque diversos estudios apuntan hacia un cierto efecto protector de mínimas cantidades de alcohol sobre la isquemia vascular cerebral y coronaria, no cabe duda de la utilización interesada de tales estudios, a menudo sesgados (factores de confusión como la edad, el sexo, el patrón de consumo, la dieta, el ejercicio, el tabaquismo y la propia definición de "abstemio", de acepciones muy diversas) y de dudosa objetividad teniendo en cuenta su habitual financiación.

El Consejo Económico y Social (CES) emitió con fecha 19 de junio de 2002 el dictamen sobre el anteproyecto de la mencionada ley, solicitado por el ministro del Interior, Mariano Rajoy con fecha 31 de mayo de 2002.

El dictamen consideraba el anteproyecto de esta ley (vulgarmente conocida como "Ley del Botellón") excesivamente sancionador y perjudicial para el sector productor. El dictamen incluye la propuesta de que sean excluidas de la aplicación de la Ley de Prevención aquellas bebidas naturales de carácter agrícola y uso alimentario que dispongan de normativas específicas.

El propio ministro de Agricultura, Sr Arias Cañete ha sido sensible a los argumentos del sector productor y se ha manifestado a favor de considerar el vino como alimento y, en consecuencia, de su eliminación de la Ley de Prevención del Consumo Indebido de Bebidas Alcohólicas.

Así las cosas, acaba de aprobarse (18 de octubre de 2002) por parte del Ministerio de Agricultura, Ganadería y Pesca el Anteproyecto de Ley de la Viña y del Vino, que, para satisfacción del sector productor, define el vino como alimento natural obtenido exclusivamente por fermentación alcohólica, total o parcial, de uva fresca, estrujada o no, o de mosto de uva. Invocando los beneficios de su consumo, se pide al Ministerio del Interior, que se le excluya de la Ley de Prevención del Consumo Indebido de Bebidas Alcohólicas.

Teniendo en cuenta que el dictamen del CES pedía la exclusión de las bebidas naturales de carácter agrícola, ¿para cuándo la cerveza?

$Y$ ya empiezan a quejarse los licoristas, esgrimiendo que en el "botellón" el 30\% del consumo lo cons- tituye el "calimocho" (vino y cola). Se sienten discriminados y anuncian que se verán obligados a presentar quejas ante la Unión Europea.

Sin duda, todo anteproyecto es mejorable y la prevención ha de encontrar un exquisito balance entre la educación y la represión. También debemos reconocer que las bebidas alcohólicas son un producto legal, cuya producción y promoción es absolutamente lícita. Sin embargo, el etanol está en todas ellas y es una sustancia potencialmente tóxica que, en medios científicos identificamos como droga psicoactiva. También sabemos que en los últimos años estamos asistiendo a un preocupante consumo de alcohol por parte de nuestros adolescentes y jóvenes durante el fin de semana. Entre los 14 y los 18 años, un 78\% ha consumido alcohol alguna vez y un $58 \%$ bebe habitualmente vino, cerveza o licores. Un 12\% tiene graves problemas con el alcohol. 2.500 personas murieron por accidente de tráfico atribuible al alcohol el año 2001 ... Y es que, con respecto al daño social, la curva de mortalidad relacionada con el alcohol asciende de forma lineal a medida que lo hace el consumo.

Pero si la mencionada ley excluye el vino y acaso la cerveza, como productos naturales y alimentarios...¿¿Qué le quedará finalmente al botellón? ¿O deberemos referirnos a la Ley del Biberón? Quizá el problema, para el sector alcoholero, es que unos cuantos chavales molestan al vecindario cuando aún deberían tomar el biberón.

Que cuando se reúnen por las noches beban alcohol, eso es lo de menos. Será que desvirtúan la dieta mediterránea e ignoran el sensato consejo de la publicidad "Bebe moderadamente; es tu responsabilidad".

$Y$ es que estos chicos no saben divertirse...

"Consumo normal es el que nos conviene a cada cual y a nuestro entorno, sin daño para nuestra salud, ni riesgo de dependencia y sin alterar el orden público."

(N. Leymarie, del Institut de Recherches Scientifiques sur les Boissons, de Francia).

"...Al lo largo del proceso de implementación del Código de Conducta de los Cerveceros len España), siempre se ha puesto el énfasis no tanto en la moderación, como en el consumo responsable, con mensajes más positivos que negativos, en particular cuando se dirigen a los jóvenes."

(J. Olalla, Cerveceros de España)

CBMC-Cerveceros de Europa. www.cbmc.org: Resumen de las presentaciones realizadas durante la Conferencia Working for responsible consumption, celebrada en Bruselas el 18 de Abril de 2002. 
Entretanto, los dos anteproyectos mencionados prosiguen su tramitación parlamentaria. Esperemos que, a pesar de que el camino parece erizado de obstáculos, la versión que finalmente se apruebe de la
Ley de Prevención del Consumo Indebido de Bebidas Alcohólicas represente una aportación significativa para reducir los problemas relacionados con el alcohol, especialmente entre nuestros jóvenes. 
